\title{
Microstructural Study of ZnO Nanostructures by Rietveld Analysis
}

\author{
Francisco Pola-Albores, Francisco Paraguay-Delgado, Wilber Antúnez-Flores, \\ Patricia Amézaga-Madrid, Edna Ríos-Valdovinos, and Mario Miki-Yoshida
}

Centro de Investigación en Materiales Avanzados, S. C. and Laboratorio Nacional de Nanotecnología, Miguel de Cervantes 120, 31109 Chihuahua, Chih., Mexico

Correspondence should be addressed to Mario Miki-Yoshida, mario.miki@cimav.edu.mx

Received 25 September 2010; Accepted 6 May 2011

Academic Editor: Xuedong Bai

Copyright ( $) 2011$ Francisco Pola-Albores et al. This is an open access article distributed under the Creative Commons Attribution License, which permits unrestricted use, distribution, and reproduction in any medium, provided the original work is properly cited.

$\mathrm{ZnO}$ nanorods were synthesized by induced seeds by chemical bath deposition using hexamethylenetetramine (HMT) as a precipitant agent and zinc nitrate $(\mathrm{ZN})$ as $\mathrm{Zn}^{2+}$ source at $90^{\circ} \mathrm{C}$. The influence of reactants ratio was studied from 2 to $0.25 \mathrm{ZN} / \mathrm{HMT}$ molar. The results obtained by scanning electron microscopy confirm that the diameter of nanorods was affected directly by the concentration of both zinc and $\mathrm{OH}^{-}$sources. Nanotubes (hollow nanorods) were obtained with high HMT concentrations and were turning over nanorods as HMT concentration decreased. Microstructural information was obtained by Rietveld refinement of grazing incidence X-ray diffraction data. These results evidence low-textured materials with oriented volumes less than $18 \%$ coming from (101) planes in Bragg condition.

\section{Introduction}

Nowadays, the interest in nanostructured $\mathrm{ZnO}$ materials has taken more relevance due to its wide range of applications and the scientific interest in polymorphism depending on synthesis conditions. Zinc oxide is a II-VI semiconductor with a band gap of $3.37 \mathrm{eV}$; it is thermally and chemically stable [1] and presents interesting properties [2-4]. These properties make the $\mathrm{ZnO}$ feasible for applications in many field, such as energy conversion [5-7], optoelectronics [8$10]$ and sensing devices [11-14], in particular when it is synthesized in one-dimensional (1D) geometry [15-17]. Among all the geometries, the most feasible for these types of applications are nanowires [1,18-20], nanobelts [21, 22], nanotubes and nanorods, and singles or arrays of them $[23,24]$. Several methods for the synthesis of nanostructured $\mathrm{ZnO}$ have been explored, but some of them are highly power demanding (in temperature or pressure) [25], or they use sophisticated processes to obtain the materials by means of a vapor-liquid-solid mechanisms [26-28], that makes the scaling-up a complicated challenge [29]. One of the most promising methods to synthesize nanomaterials is the chemical bath deposition (CBD), which is a non sophisticated, low-temperature $\left(<100^{\circ} \mathrm{C}\right)$, and low-cost wet route $[2,25,30,31]$. Additionally, $\mathrm{CBD}$ has a high degree of versatility to modify several parameters, such as temperature, $\mathrm{pH}$ [32], and concentration of reactants; which in turn could modify the morphology, size, and shape of the nanomaterials [33].

In this work, we have synthesized $\mathrm{ZnO}$ nanorods by $\mathrm{CBD}$ and studied the influence of hexamethylenetetramine (HMT) and zinc concentration in their morphology and microstructure. Additionally, the microstructure analysis was realized with Rietveld refinement, using asymmetric diffraction with the grazing incidence X-ray diffraction (GIXRD) technique. Hence, we discuss the low-volumeoriented fraction associated to the preferred orientation obtained, and also we compare sizes obtained by refinement versus scanning electron microscopy (SEM) images. 
TABLE 1: Concentrations of HMT and ZN in each reaction system used in the synthesis of $\mathrm{ZnO}$ nanorods by CBD.

\begin{tabular}{lccc}
\hline \multicolumn{4}{c}{ Total volume $=10 \mathrm{~mL}}$. \\
Sample & $\begin{array}{c}\text { HMT }(\mathrm{mol} / \mathrm{L}) \\
\times 10^{3}\end{array}$ & $\begin{array}{c}\mathrm{ZN}(\mathrm{mol} / \mathrm{L}) \\
\times 10^{3}\end{array}$ & Ratio ZN/HMT \\
\hline Z01 & 30.0 & 60.2 & 2.00 \\
Z02 & 30.0 & 52.7 & 1.75 \\
Z03 & 30.0 & 45.1 & 1.50 \\
Z04 & 30.0 & 37.6 & 1.25 \\
Z05 & 30.0 & 30.5 & 1.01 \\
Z06 & 30.0 & 22.6 & 0.75 \\
Z07 & 30.0 & 15.0 & 0.50 \\
Z08 & 30.0 & 7.5 & 0.25 \\
Z09 & 45.1 & 30.0 & 0.67 \\
Z10 & 60.2 & 30.0 & 0.50 \\
Z11 & 75.2 & 30.0 & 0.40 \\
Z12 & 90.3 & 30.0 & 0.34 \\
Z13 & 105.3 & 30.0 & 0.30 \\
Z14 & 120.4 & 30.0 & 0.25 \\
\hline
\end{tabular}

\section{Experimental Details}

2.1. Seed Synthesis by Sol-Gel. A solution of $0.01 \mathrm{~mol} / \mathrm{L}$ of $\mathrm{NaOH}($ SIGMA, 98+\%) in methanol was dropped into a $50 \mathrm{~mL}$ of $0.005 \mathrm{~mol} / \mathrm{L}$ dilution of zinc acetate dehydrated in ethanol (Aldrich Chemical Company Inc., 98+\%) contained in a three-necked flask with condenser heated at $60^{\circ} \mathrm{C}$ with stirring. The reaction was performed until the solution became cloudy due to the suspended $\mathrm{ZnO}$ particles. The substrates were previously washed and sonicated in methanol two times in periods of $30 \mathrm{~min}$. Afterward, the borosilicate $(15 \times 5 \mathrm{~mm})$ substrates were dipped into the colloidal $\mathrm{ZnO}$ solution, and then they were dried inclined at room temperature. Finally, they were calcined at $500^{\circ} \mathrm{C}$ inside an ambient-controlled furnace Neytech for $30 \mathrm{~min}$ at around 16 Torr of pressure.

2.2. $\mathrm{ZnO}$ Nanorods Growth via CBD. Two experiments with a pair effect of hexamethylenetetramine and zinc nitrate (ZN) were carried out. First experiment consisted in eight samples with constant concentration of HMT and variable $\mathrm{ZN}$ content. In the second experiment, six samples with the $\mathrm{ZN}$ amount constant while the HMT concentration was varied. The conditions of seed synthesis and impregnation over the substrate were the same for all cases. Table 1 presents the concentrations of reactants utilized in the synthesis.

The growth of $\mathrm{ZnO}$ nanorods was realized using a modified method of that reported by Liu and Zhou [34]. The seed-coated substrates were introduced into a $15 \mathrm{~mL}$ culture tubes (with screw caps) previously added with constant volume of PEG $(0.6 \mathrm{~mL})$. The initial reactants were HMT $0.5 \mathrm{~mol} / \mathrm{L}$ (Sigma-Aldrich, 99+\%), $\mathrm{Zn}\left(\mathrm{NO}_{3}\right)_{2} \cdot \mathrm{XH}_{2} \mathrm{O}($ AlfaAesar, 99\%) $0.25 \mathrm{~mol} / \mathrm{L}$ and polyethylene glycol (PEG) (J. T. Baker) with $\mathrm{PM}=20,000$ at around $10 \mathrm{wt} \%$. We mixed adequate volumes of these solutions and tridistilled water in the tubes in order to obtain a total volume of $10 \mathrm{~mL}$, with the final concentrations presented in Table 1. Finally, the tubes were closed to avoid contamination, and they were placed in a temperature-controlled water bath. The reaction was carried out for $3 \mathrm{~h}$ at $90^{\circ} \mathrm{C}$. After that, the reactors were cooled to room temperature. At the end, the $\mathrm{pH}$ in each reactor was registered, and the substrates were rinsed with tridistilled water, then they were calcined at $360^{\circ} \mathrm{C}$ inside the same ambient-controlled furnace for $30 \mathrm{~min}$ at around 16 Torr of pressure.

2.3. Characterization. The morphology of $\mathrm{ZnO}$ nanorods was studied using a field emission scanning electron microscope JEOL-JSM 7401-F operated at $3 \mathrm{keV}$. The micrographs were used to measure length $(L)$ and diameter $(D)$ to obtain $L / D$ ratio statistics (56 to 100 individuals for each sample). On the other hand, in order to improve the imaging contrast, a piece of $\mathrm{Si}$ wafer was dipped with $\mathrm{ZnO}$ seeds following the sequence described above. The morphology of these seeds was studied by SEM.

Diffraction analysis for phase identification and structural refinement were carried out, in GIXRD configuration, using a XPert-Pro panalytical diffractometer operated at $40 \mathrm{kV}$ and $35 \mathrm{~mA}$, equipped with $\mathrm{Cu} \mathrm{K}_{\alpha}$ source at $1.54187 \AA$ and PW3011/20 detector. The diffractometer was configured in $\omega-2 \theta$ mode, with incidence angle $(\omega)$ settled at $1^{\circ}$. The $2 \theta$ range was between 25 and 95 degrees with $0.02^{\circ}$-step size and $12 \mathrm{~s}$ of step time. Phase identification was realized matching diffracted peaks with PDF cards.

2.4. The Rietveld Refinement Method on GIXRD Configuration. Due to the extensive use of Rietveld refinement programs in diffraction analysis, we used this useful tool for obtaining crystallites size and texture at GIXRD conditions (commonly used for thin films and coatings). The refinement was done with the FullProf (FP) free available software [35], with a modified version of Thompson-Cox-Hastings pseudo-Voigt (TCHZ) function profile. The instrumental resolution function for broadening effects was obtained using a silicon standard from NIST and fitted with the WinPlotr software [36]. Any treatment of smoothing or filtering was carried out on the experimental data. However, due to the asymmetrical condition of GIXRD, that gives higher intensity than those obtained in Bragg-Brentano (BB) configuration, the experimental intensities were corrected to the symmetrical Bragg reflection using the James factor [3739]. This factor relates the asymmetrical and symmetrical diffraction intensities according to

$$
J(2 \theta)=\frac{I_{\text {asym }}(2 \theta)}{I_{\text {sym }}(2 \theta)}=\frac{2}{[1+\operatorname{sen}(\omega) / \operatorname{sen}(2 \theta-\omega)]},
$$

where $\omega$ is the incidence angle. In relation to this, Toraya and Okuda [37] multiplied the conventional intensity formula of powder diffraction in their PFLS Rietveld program by $J(2 \theta)$ in order to employ directly GIXRD data. In our approach, the experimental intensity $I_{\text {asym }}(2 \theta)$ was divided by $J(2 \theta)$; these corrected values were used in the refinement. Afterwards, we can assume that preferred orientation (PO) subroutine of FP 


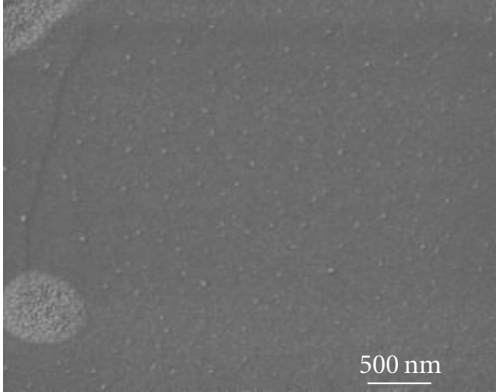

(a)

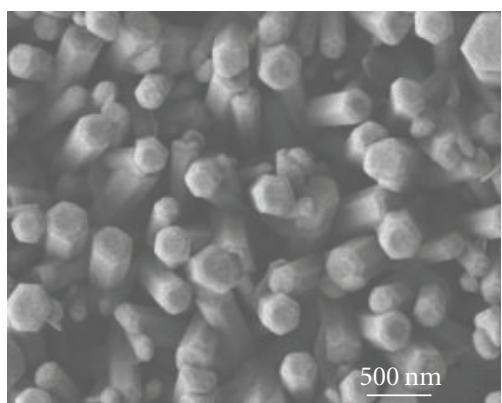

(b)

FIGURE 1: (a) SEM micrographs of ZnO prepared by sol-gel and deposited by wet immersion over a glass substrate. Seed-coated substrate was calcined at $500^{\circ} \mathrm{C}$. (b) $\mathrm{ZnO}$ nanorods grown by $\mathrm{CBD}$ using a typical $\mathrm{ZnO}$ seed-coated substrate.

software, available only for BB configuration, could be used with the corrected intensity of experimental diffraction data.

We have considered that size broadening has only the Lorentzian component $(Y+F(S z) / \cos (\theta))$ [40], and microstrains were neglected. The PO function used in Rietveld analysis was the March-Dollase type, commonly used for low-textured materials [41]

$$
P(\phi)=\left(G_{1}^{2} \cos ^{2} \phi+\frac{\sin ^{2} \phi}{G_{1}}\right)^{-3 / 2},
$$

where $G_{1}$ is a refinable coefficient and represents the degree of texture; $\phi$ is the acute angle between the scattering vector $\mathrm{g}$ and the normal to (hkl) plane. According to (2), PO is achieves only if $P(\phi)>1$, and this condition can be present if $G_{1}<1$ (in platelet-like habit) or $G_{1}>1$ (needle-like habit); $G_{1}=1$ means no texture present. In this case, four PO models $\vec{P}_{002}, \vec{P}_{101}, \vec{P}_{110}$, and $\vec{P}_{100}$ were chosen for each sample in order to fit the PO function, and only one was taken as representative of the sample. The oriented volume fraction was calculated normalizing the (2) and integrating [42]

$$
V_{\text {Oriented }}=\int_{0}^{\phi_{1}}(P(\phi)-1) \sin \phi \mathrm{d} \phi \quad(\text { for } G 1<1),
$$

where $\phi_{1}$ is the value when $P\left(\phi_{1}\right)=1$. If $G_{1}>1$, integration limits change from $\phi_{1}$ to $\pi / 2$.

Another diffraction pattern of previously synthesized $\mathrm{ZnO}$ was taken as reference of a randomized material due to the fact that its relative intensity matchs with the PDF card no. 36-1451. This material was used to approximate a pole density (PD) of each sample according to Harris method [43]

$$
R\left(\vec{g}_{i}\right)=\frac{\psi_{i}}{1 / N \sum_{i}^{N} \psi_{i}},
$$

where $\psi_{i}=I\left(\vec{g}_{i}\right) / I_{r}\left(\vec{g}_{i}\right), I\left(\vec{g}_{i}\right)$ is the diffracted intensity of (hkl) plane and $I_{r}\left(\vec{g}_{i}\right)$ is the intensity of each diffracted peak of the sample. The PD data file was used by FP input code control (Algorithm 1) for internal intensity calculation.

\section{Results and Discussion}

3.1. Seed Analysis. Figure 1(a) shows SEM micrograph of $\mathrm{ZnO}$ seeds deposited over a glass substrate and calcined at $500^{\circ} \mathrm{C}$. Most of seeds dimensions are in $15-30 \mathrm{~nm}$ (diameter), and some of them reach the $50 \mathrm{~nm}$. The uniformity of particles is evident in the majority of substrate surface; however, unavoidable local inhomogeneities are present in the synthesis as a consequence of nonuniform evaporation step.

On the other hand, the thermal treatment at $500^{\circ} \mathrm{C}$ in low-vacuum atmosphere has mainly three effects: (i) first of all, it generated more dense particles as a consequence of liquid evaporation and elimination of residues from the solgel reaction, (ii) secondly, it increased the size of particles from colloidal agglomerates until final sizes $(<30 \mathrm{~nm})$, and (iii) finally, it ensured strong adherence of seeds on the glass substrate. The seeds act as a nucleation center with low-activation energy barrier for anisotropic growth of $\mathrm{ZnO}$ nanorods along [001] direction $[6,16,44]$.

Figure 1(b) shows semialigned nanorods grown from $\mathrm{ZnO}$ nuclei; the electrostatic attraction of ionic species $\left(\mathrm{Zn}^{2+}\right.$ and $\mathrm{OH}^{-}$) in polar surfaces causes nucleation [25] and consequently an anisotropic growth.

3.2. Morphology and Growth of $\mathrm{ZnO}$ Nanorods. Figure 2 (Z1-Z8) shows secondary electron SEM micrographs of the nanorods as a function of $\mathrm{ZN}$ concentration. It can be observed systematic changes in the shape of the nanorods, due to the variation of precursor concentration. It demonstrates the importance of the $\mathrm{ZN}$ concentration to obtain a particular shape of nanorods. First 3 images (Z1-Z3) show slightly porous nanorods, and the diameters are not uniform. In the case of Z2, most of the nanorods are broken approximately at the middle section. It is probably due to a thermal effect, as a result of the porosity and less uniformity generated in the nanorods at these concentration ratio. According to Chen and Gao [45], the reaction can be expressed as follows:

$$
\begin{gathered}
\left(\mathrm{CH}_{2}\right)_{6} \mathrm{~N}_{4}+6 \mathrm{H}_{2} \mathrm{O} \\
\mathrm{NH}_{3}+\mathrm{H}_{2} \mathrm{O} \longleftrightarrow \mathrm{HCHO}_{4}^{+}+\mathrm{OH}^{-}, \\
2 \mathrm{OH}^{-}+\mathrm{Zn}^{2+} \longrightarrow \mathrm{ZnO}_{(\mathrm{s})}+\mathrm{H}_{2} \mathrm{O} .
\end{gathered}
$$




\section{COMM NANORODS}

! Current global Chi2 (Bragg contrib.) $=1.356$

! Files $=>$ DAT-file: $\mathrm{t} 2, \quad$ PCR-file: $\mathrm{t} 2$

!Job Npr Nph Nba Nex Nsc Nor Dum Iwg Ilo Ias Res Ste Nre Cry Uni Cor Opt Aut

$\begin{array}{lllllllllllllllllll}0 & 7 & 1 & 0 & 1 & 0 & 1 & 0 & 0 & 0 & 1 & 4 & 0 & 0 & 0 & 0 & 0 & 0 & 1\end{array}$

1

! Resolution file for Pattern\# 1

Siw1_XPert.IRF

!Ipr Ppl Ioc Mat Pcr Ls1 Ls2 Ls3 NLI Prf Ins Rpa Sym Hkl Fou Sho Ana

$\begin{array}{llllllllllllllllll}0 & 0 & 1 & 0 & 1 & 0 & 4 & 0 & 0 & 3 & 10 & 0 & 1 & 1 & 0 & 0 & 1\end{array}$

!

! lambda1 Lambda2 Ratio Bkpos Wdt Cthm muR AsyLim Rpolarz ->Patt\# 1

$\begin{array}{lllllllll}1.540560 & 1.544390 & 0.4729 & 20.000 & 5.5000 & 0.7998 & 0.0000 & 95.00 & 0.0000\end{array}$

!

!NCY Eps R_at R_an R_pr R_gl Thmin Step Thmax PSD Sent0

$\begin{array}{lllllllllll}50 & 0.25 & 0.95 & 0.95 & 0.95 & 0.95 & 25.1300 & 0.020006 & 94.9900 & 0.000 & 0.000\end{array}$

!

! Excluded regions (LowT HighT) for Pattern\# 1

$75.00 \quad 95.00$

!

$!$

!

15 !Number of refined parameters

! Zero Code SyCos Code SySin Code Lambda Code MORE - >Patt\# 1

$\begin{array}{lllllllll}0.18066 & 61.0 & -0.10181 & 0.0 & -0.00081 & 0.0 & 0.000000 & 0.00 & 0\end{array}$

! Background coefficients/codes for Pattern\# 1

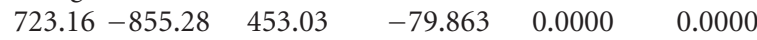

$\begin{array}{llllll}21.000 & 31.000 & 41.000 & 51.000 & 0.000 & 0.000\end{array}$

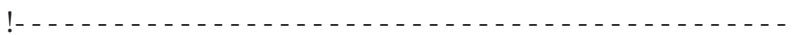

! Data for PHASE number: $1==>$ Current R_Bragg for Pattern\# 1: 3.02

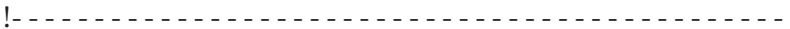

Zincite $\mathrm{ZnO}$

!

!Nat Dis Ang Pr1 Pr2 Pr3 Jbt Irf Isy Str Furth ATZ Nvk Npr More

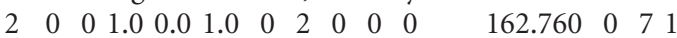

!

!Jvi Jdi Hel Sol Mom Ter Brind RMua RMub RMuc Jtyp Nsp_Ref Ph_Shift N_Domains

$\begin{array}{llllllllllllllll}5 & 0 & 0 & 0 & 0 & 0 & 1.0000 & 0.000 & 0.0000 & 0.0000 & 0 & 0 & 0 & 0\end{array}$

!

P $63 \mathrm{~m} \mathrm{c} \quad<-$-Space group symbol

!Atom Typ X $\quad \mathrm{Y} \quad \mathrm{Z}$ Biso Occ In Fin N_t Spc/Codes

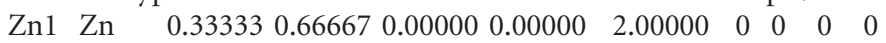

$\begin{array}{lllll}0.00 & 0.00 & 0.00 & 0.00 & 0.00\end{array}$

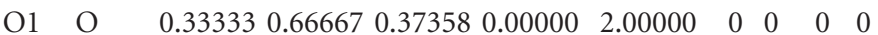

$\begin{array}{lllll}0.00 & 0.00 & 121.00 & 0.00 & 0.00\end{array}$

!- - - > Profile Parameters for Pattern \# 1

! Scale Shape1 Bov Str1 Str2 Str3 Strain-Model

$\begin{array}{llllllll}0.84699 \mathrm{E}-04 & 0.00000 & 1.55472 & 0.00000 & 0.00000 & 0.00000 & 0\end{array}$

$\begin{array}{llllll}11.00000 & 0.000 & 151.000 & 0.000 & 0.000 & 0.000\end{array}$

$! \quad \mathrm{U} \quad \mathrm{V} \quad \mathrm{W} \quad \mathrm{X} \quad \mathrm{Y}$ GauSiz LorSiz Size-Model

$\begin{array}{lllllllll}0.000000 & 0.000000 & 0.000000 & 0.000000 & 0.016111 & 0.000000 & 0.560394 & -1\end{array}$

$\begin{array}{lllllll}0.000 & 0.000 & 0.000 & 0.000 & 141.000 & 0.000 & 131.000\end{array}$

! a b c alpha beta gamma \#Cell Info

$\begin{array}{llllll}3.251389 & 3.251389 & 5.209196 & 90.000000 & 90.000000 & 120.000000\end{array}$

$\begin{array}{llllll}71.00000 & 71.00000 & 81.00000 & 0.00000 & 0.00000 & 71.00000\end{array}$

! Pref1 Pref2 Asy1 Asy2 Asy3 Asy4 S_L D_L

$\begin{array}{llllllll}0.92047 & 0.00000 & -0.11362 & -0.02108 & 0.00000 & 0.00000 & 0.05815 & 0.01090\end{array}$

$\begin{array}{llllllll}91.00 & 0.00 & 101.00 & 111.00 & 0.00 & 0.00 & 0.00 & 0.00\end{array}$

$\begin{array}{llll}0.0000 & 0.0000 & 2.0000 \quad \text { Platelet-Needle vector (Size) }\end{array}$

! 2Th1/TOF1 2Th2/TOF2 Pattern \# 1

$25.130 \quad 75.000 \quad 1$ 

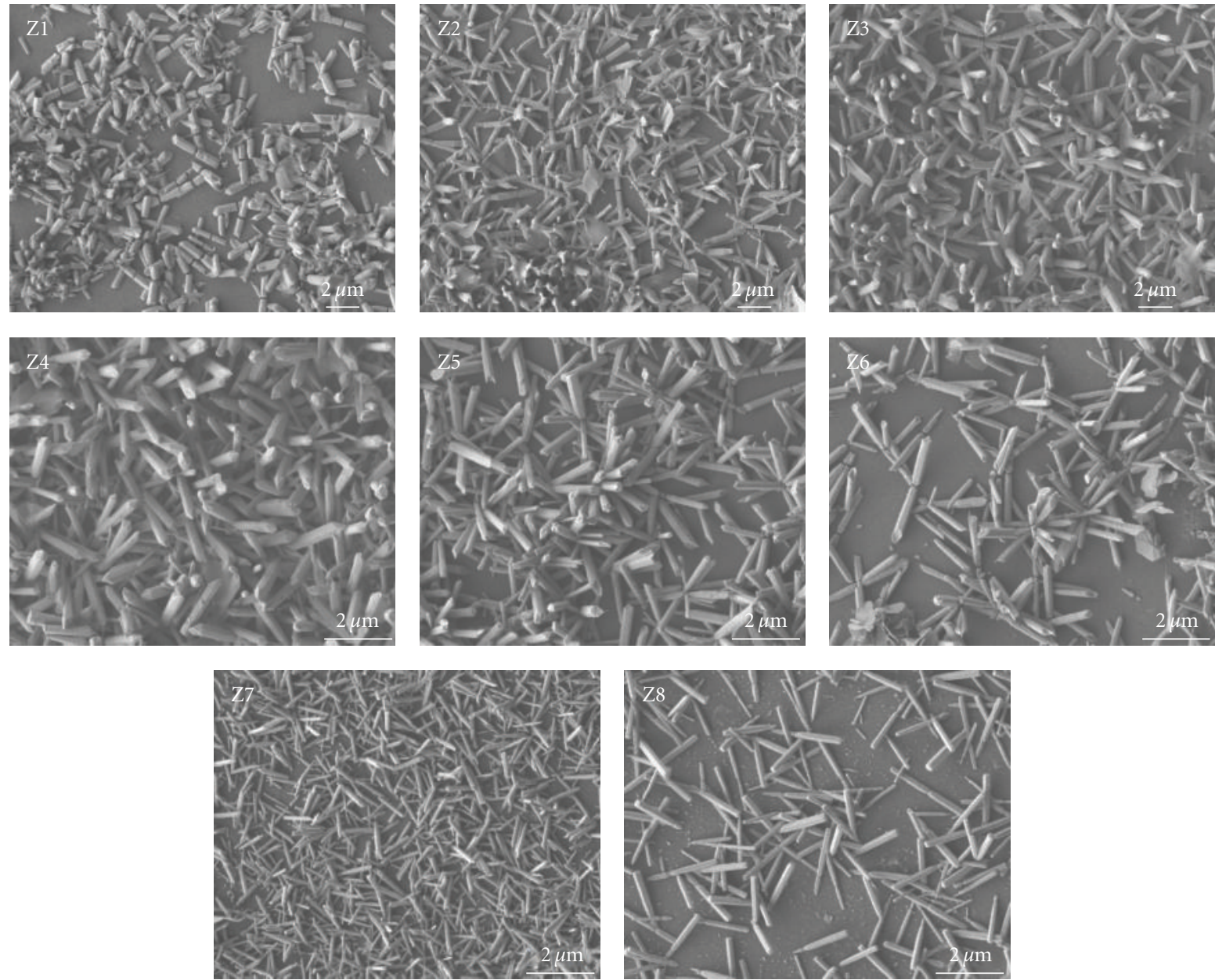

FIgURE 2: SEM images of $\mathrm{ZnO}$ nanorods synthetized by CBD varying the concentration of $\mathrm{ZN}$ with constant concentration of $\mathrm{HMT}(30 \times$ $10^{-3} \mathrm{~mol} / \mathrm{L}$ ). Nominal concentrations of ZN were $60,53,45,38,31,23,15$, and $8 \times 10^{-3} \mathrm{~mol} / \mathrm{L}$ for Z1 to Z8, respectively.

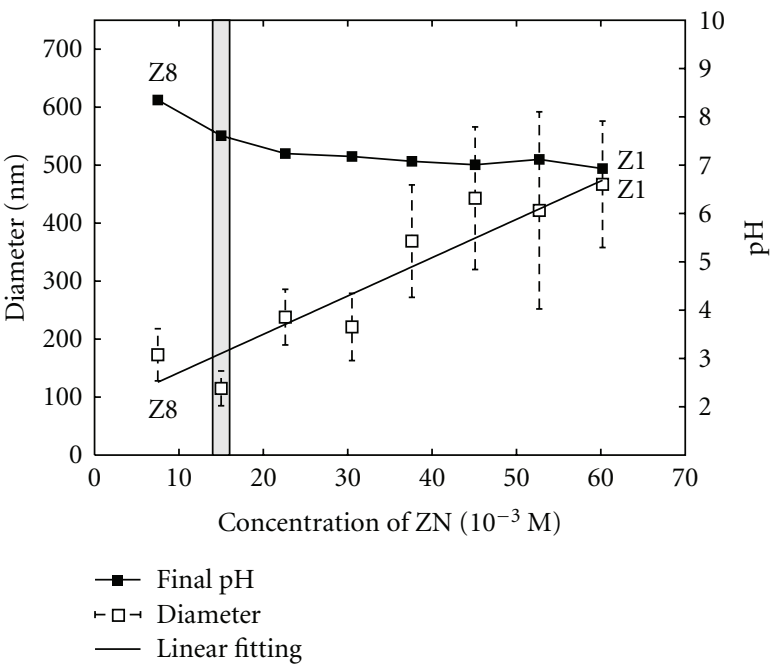

Figure 3: Diameters of nanorods and final $\mathrm{pH}$ as influence of the concentration of $\mathrm{ZN}$ in $\mathrm{Z1}$ to $\mathrm{Z} 8$ samples. Gray zone represents best conditions of diameter achieved.
From these equations, it can be shown how HMT two-step hydrolysis generates $\mathrm{OH}^{-}$species that potentially react with $\mathrm{Zn}^{2+}$ cations which are coming from the $\mathrm{ZN}$. One molecule of HMT reacts with two $\mathrm{Zn}^{2+}$ cations and produces two molecules of $\mathrm{ZnO}$. This stoichiometric ratio corresponds to Z01 sample. Hence, the Z02 to Z08 samples are under stoichiometric ratio (HMT excess). Secondary electron SEM micrographs of samples Z01 to Z08 show basically a decreases of the diameter of rods as the $\mathrm{ZN}$ concentration decrease. This could be explained as the competition of the $\mathrm{Zn}^{2+}$ ions; near the stoichiometric region, there is no excess of species, and competition takes place in a $\mathrm{ZnO}$ seed face that induces growing by $\mathrm{OH}^{-}$. According to our synthesis condition, we consider a constant number of seeds particles available on the substrate (constant area). Then, if ZN concentration decreases over a constant available seed induction faces, thin nanorods growing in [001] direction are expected. Figure 3 shows average diameter of nanorods (obtained by direct account of nanorods population) and final $\mathrm{pH}$ of samples versus $\mathrm{ZN}$ concentration. It is evident that the diameter of nanorods diminished systematically as the growing agent $(\mathrm{ZN})$ decreased. This is in agreement 

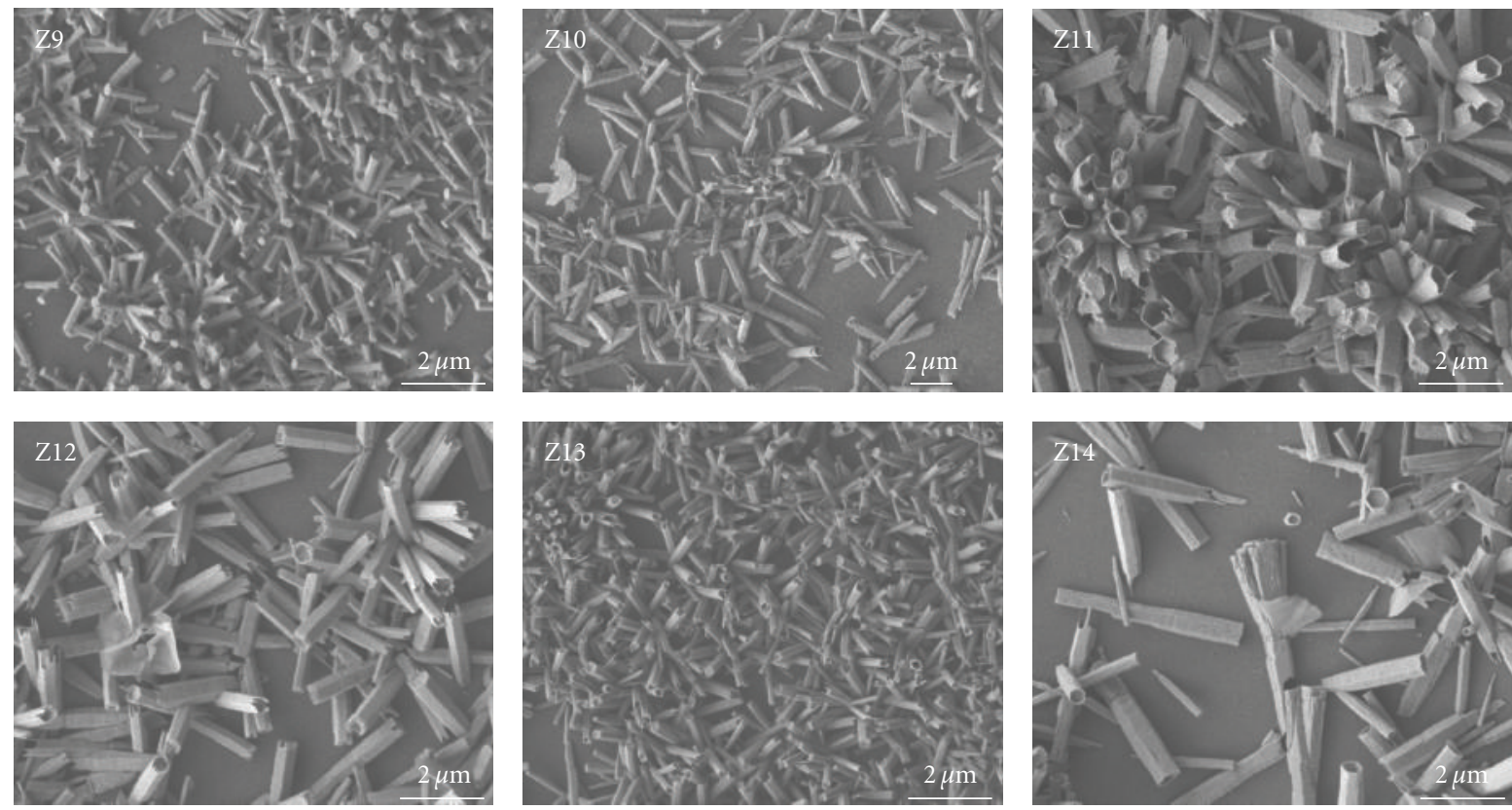

FIGURE 4: SEM images of $\mathrm{ZnO}$ nanorods synthetized by CBD varying concentration of HMT with constant concentration of $\mathrm{ZN}(30 \times$ $10^{-3} \mathrm{~mol} / \mathrm{L}$ ). Nominal concentrations of HMT were 45, 60, 75, 90, 105, and $120 \times 10^{-3} \mathrm{~mol} / \mathrm{L}$ for Z9 to Z14, respectively.

with data obtained from reaction time variation reported elsewhere [46, 47], and also it is consistent with material conservation law. According to the graph, final $\mathrm{pH}$ increased from almost neutral (6.9) in $\mathrm{Z1}$ to alkaline (8.4) in Z8. This fact coincides with (5) to (7); when the concentration of cation $\mathrm{Zn}^{2+}$ is low, the amount of non reacted hydroxyl $\left(\mathrm{OH}^{-}\right)$formed from HMT hydrolysis increases, and then the $\mathrm{pH}$ increases as well.

Figure 4 shows SEM micrographs of nanorods synthesized in the second experiment. Although the ZN/HMT ratios were similar in some samples (e.g., Z07 and Z10 have both 0.5 of ZN/HMT ratio), the concentrations of reactants vary, and therefore, these samples also presented structural and morphological differences.

In Figure 4, SEM micrographs of samples Z10 to Z14 with a hollow rod structure (nanotube-like) are shown, and their wall thicknesses were ca. $30 \mathrm{~nm}$, present neither in Z9 nor in the previous experiment (samples Z1 to Z8).

Nanotube-like structure appears in Z10 with thin wall tip; however, most of them are destroyed or not well defined. We have commented the presence of $\mathrm{ZN}$, as a source of $\mathrm{Zn}^{2+}$, necessary for the growing of nanorods. In these experiments, as the HMT content increased, the reaction required more water (via HMT hydrolysis), then water concentration constituted a limiting factor in the chemical reaction. In the constant volume reaction $(10 \mathrm{~mL})$, the total water (added and used for dilution) was not enough for the hydrolysis (5) and (6), and the chemical reaction was limited in samples Z12 to Z14.

Accordingly, Z12 to Z14 presented similar nanotubelike morphologies, as it can be seen in SEM micrographs (Figure 4). In Figure 5, it is shown that nanorods diameter increased as HMT concentration increased (samples Z9 to

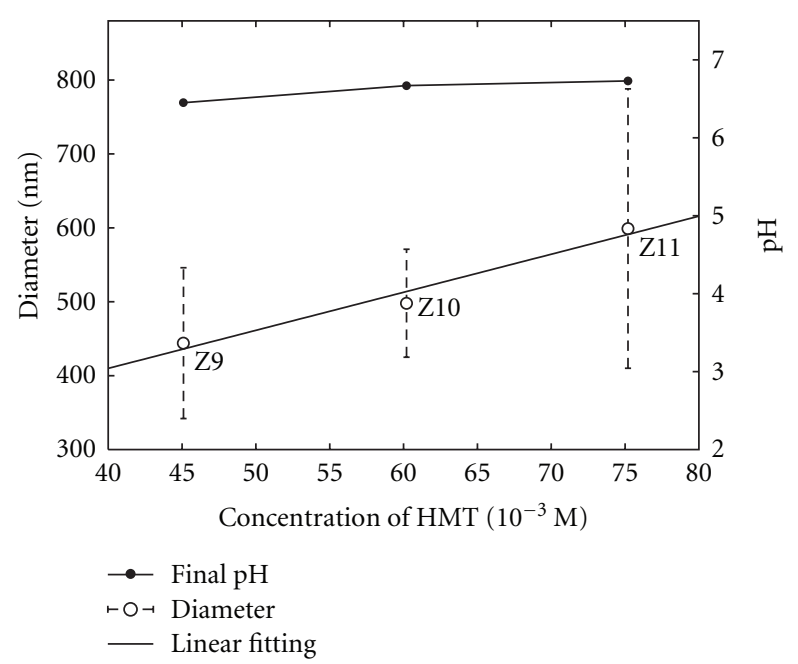

FIGURE 5: Diameter of nanorods and final $\mathrm{pH}$ as influence of the concentration of HMT in Z9 to Z11 samples.

Z11); due to limited reaction progress, samples Z12 to Z14 were excluded. Indeed, it can be observed that influence of HMT concentration in diameter of nanorods was lower than the influence of $\mathrm{ZN}$ in previous experiment ( $\mathrm{Z} 1$ to $\mathrm{Z8}$ ). Final $\mathrm{pH}$ values presented low variation and were around 7.0.

A hypothesis of hollow formation mechanism is based on amphoteric properties of $\mathrm{ZnO}$ when it redissolves to form zincates $\left(\mathrm{ZnO}_{2}^{-2}\right)$ or hydroxo complexes as $\mathrm{Me}^{+}\left[\mathrm{Zn}(\mathrm{OH})_{3}\right]^{-}$ in basic media $[33,48]$. In a medium with $\mathrm{Zn}^{2+}$ cations and $\mathrm{OH}^{-}$species coming from HMT hydrolysis, nanorod growth starts; however, a continuous supply of $\mathrm{OH}^{-}$prevails during the reaction. Then, in the basic media, $\mathrm{ZnO}$ complexes could 


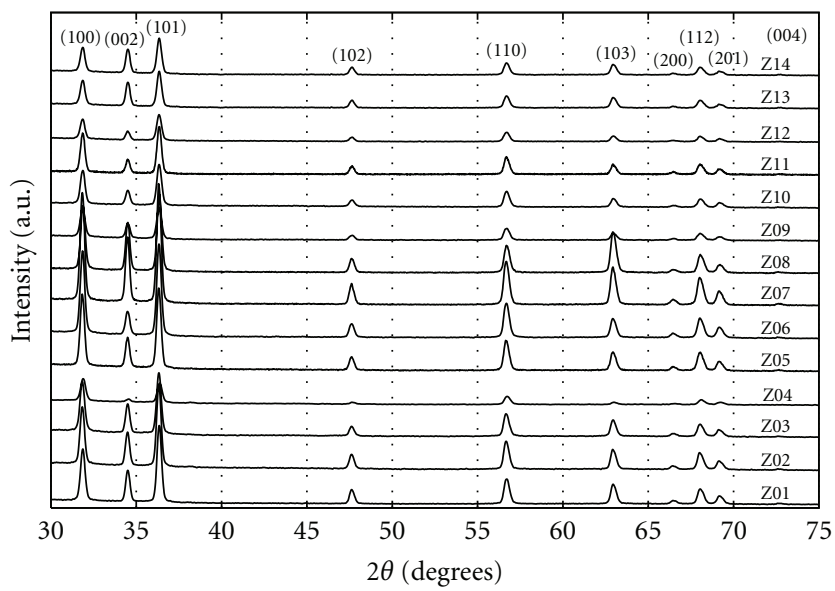

FIGURE 6: Diffraction patterns of $\mathrm{ZnO}$ nanorod-coated substrates. Samples are shown in Table 1.

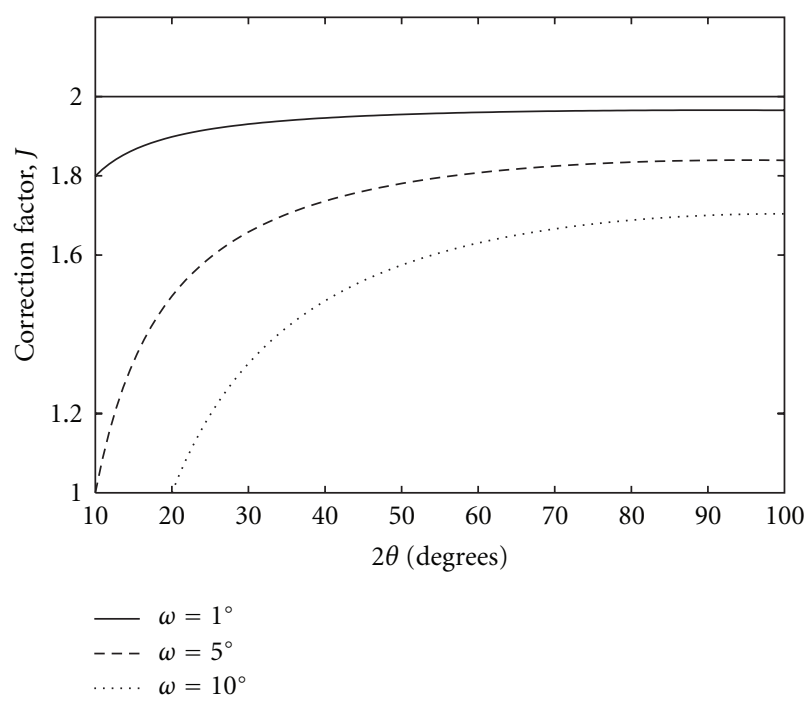

Figure 7: Correction factor $J$ as a function of $2 \theta$, for different X-ray incidence angles $(\omega)$.

be formed and redissolution phenomena of nanorods in polar face (002) could take place. Finally, hollow nanorods could be formed. After redissolution, $\mathrm{pH}$ was lowered around 7.0 , as it was observed experimentally.

3.2.1. Phase Analysis. GIXRD patterns of $\mathrm{ZnO}$ nanorod samples are shown in Figure 6. Phase analysis was similar to conventional powder methods [49]. The only phase detected corresponded to crystalline hexagonal wurtzite type structure (PDF card no. 36-1451). All diffractograms show relatives intensities as a typical $\mathrm{ZnO}$ powder sample.

The nonuniformity of the material observed in SEM images is also reflected in peaks intensity of diffractograms. The (002) planes reach their minimum intensity in Z04 sample probably due to a poorly coated substrate; in other hand, (002) reflection becomes the most intense in Z07 sample where more amount of material was present.

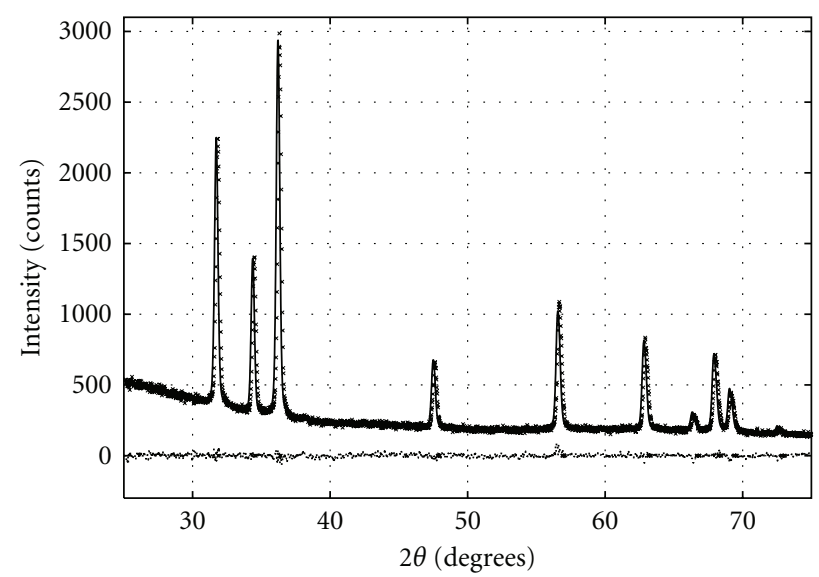

$\times$ Corrected intensity

- Calculated

..... Difference

FIGURE 8: Experimental and simulated diffraction pattern with Rietveld refinement using FullProf of $\mathrm{ZnO}$ nanorods-coated substrate (Z2 sample).

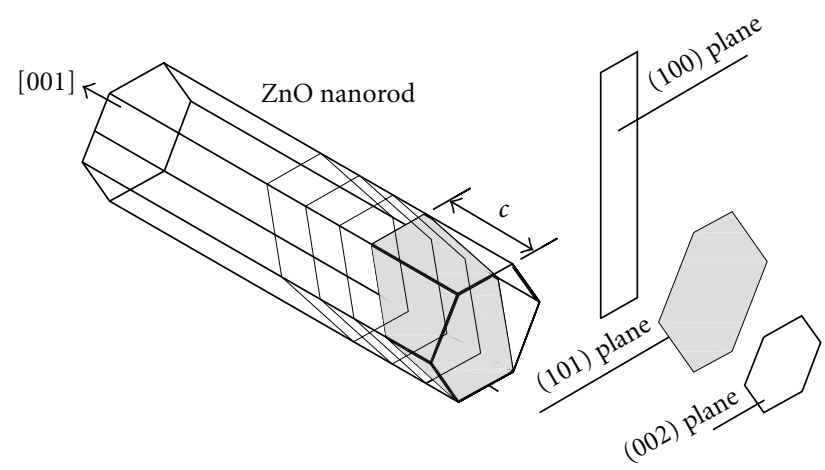

c: Lattice parameter

Figure 9: Geometric comparison of low-index planes in a $\mathrm{ZnO}$ nanorod.

The effect of hollow nanorods is evident in GIXRD patterns of samples Z9 to Z14. If hollows are present, the amount of (100), (002), and (101) diffracting planes diminishes directly; as a consequence, peak intensity decreases. Intensities in diffractograms of $\mathrm{ZnO}$ nanorods in $\mathrm{Z1}-\mathrm{Z8}$ samples are higher than those observed in nanotube-like samples Z9-Z14.

Additionally, diffractograms of samples Z11 to Z14 are similar; they show consistency with the limited reaction progress for these samples, as discussed before.

3.2.2. Rietveld Analysis. Figure 7 shows James factor $J(2 \theta)$ at different incidence angles, as a function of $2 \theta$. Only a slight variation $(<10 \%)$ is observed at low $2 \theta\left(<30^{\circ}\right)$ for $\omega=1^{\circ}$. According to the graph, the factor varies considerably at low $2 \theta$, when incidence angle increases $\left(\omega \geq 5^{\circ}\right)$. A simulated and experimental (corrected) diffractogram are shown in Figure 8. In our case, the correction was approximately 
TABLE 2: Results of Rietveld refinement.

\begin{tabular}{|c|c|c|c|c|c|c|c|c|c|c|c|c|}
\hline \multirow{2}{*}{ Sample } & \multirow{2}{*}{$\mathrm{Rp}$} & \multirow{2}{*}{ Rwp } & \multirow{2}{*}{ GofF } & \multicolumn{3}{|c|}{ Lattice parameters } & \multicolumn{2}{|c|}{ Preferred orientation } & \multicolumn{2}{|c|}{ Size parameters } & \multirow{2}{*}{$B$ overall $\left(\AA^{2}\right)$} & \multirow{2}{*}{$Z$ Oxygen } \\
\hline & & & & $a(\AA)$ & $c(\AA)$ & $c / a$ & G1 (101) & Vol. oriented \% & $Y$ & $S(Z)$ & & \\
\hline $\mathrm{Z} 1$ & 15.5 & 12.2 & 0.8 & 3.247 & 5.203 & 1.602 & 0.857 & 8.9 & 0.025 & 0.471 & 1.64 & 0.374 \\
\hline $\mathrm{Z} 2$ & 17.6 & 12.8 & 0.8 & 3.251 & 5.209 & 1.602 & 0.828 & 10.9 & 0.021 & 0.465 & 1.43 & 0.375 \\
\hline $\mathrm{Z3}$ & 21.2 & 15.0 & 0.9 & 3.250 & 5.206 & 1.602 & 0.830 & 10.5 & 0.026 & 0.695 & 2.09 & 0.370 \\
\hline $\mathrm{Z} 4$ & 50.7 & 28.2 & 0.8 & 3.254 & 5.212 & 1.602 & 0.730 & 18.0 & 0.369 & -5.20 & 2.37 & 0.367 \\
\hline $\mathrm{Z} 5$ & 17.0 & 12.6 & 0.9 & 3.252 & 5.211 & 1.602 & 0.821 & 11.3 & 0.038 & 0.137 & 1.04 & 0.374 \\
\hline Z6 & 16.6 & 12.9 & 0.9 & 3.251 & 5.209 & 1.602 & 0.816 & 11.7 & 0.041 & 0.116 & 1.47 & 0.375 \\
\hline $\mathrm{Z7}$ & 12.6 & 10.7 & 1.0 & 3.252 & 5.212 & 1.602 & 0.861 & 8.6 & 0.031 & 0.414 & 0.65 & 0.378 \\
\hline Z8 & 14.3 & 12.1 & 0.9 & 3.251 & 5.212 & 1.603 & 0.922 & 4.7 & 0.025 & 0.576 & 1.11 & 0.370 \\
\hline Z9 & 35.0 & 22.6 & 0.9 & 3.249 & 5.205 & 1.602 & 0.799 & 12.9 & 0.045 & 0.397 & 2.30 & 0.373 \\
\hline Z10 & 27.9 & 19.1 & 0.9 & 3.250 & 5.208 & 1.602 & 0.801 & 12.7 & 0.038 & 0.217 & 1.66 & 0.369 \\
\hline Z11 & 23.6 & 17.4 & 1.2 & 3.251 & 5.210 & 1.602 & 0.778 & 14.4 & 0.036 & 0.152 & 1.56 & 0.376 \\
\hline Z12 & 37.5 & 23.8 & 0.8 & 3.245 & 5.198 & 1.602 & 0.762 & 15.5 & 0.023 & 0.625 & 2.70 & 0.364 \\
\hline Z13 & 29.1 & 20.0 & 0.9 & 3.251 & 5.208 & 1.602 & 0.899 & 6.1 & 0.019 & 0.765 & 2.30 & 0.372 \\
\hline Z14 & 32.8 & 21.5 & 0.9 & 3.243 & 5.196 & 1.602 & 0.809 & 12.2 & 0.020 & 0.543 & 2.03 & 0.372 \\
\hline
\end{tabular}

TABLE 3: Inclinations of $\mathrm{ZnO}$ rod populations in Bragg condition at low angles using GIXRD $\left(\omega=1^{\circ}\right)$. Units in degrees.

\begin{tabular}{cccc}
\hline Plane & $\theta$ & $2 \theta_{\text {Bragg, } i}$ & $\gamma_{i}$ \\
\hline$(100)$ & 0 & 31.77 & -15.37 \\
$(002)$ & 90 & 34.42 & 73.29 \\
$(101)$ & $\tan ^{-1}(a / c)=31.9$ & 36.25 & 14.34 \\
\hline
\end{tabular}

to divide by 2 the experimental GIXRD data. No peak broadening was affected by the correction.

The main results of Rietveld refinement are summarized in Table 2; additionally, typical FP input control code is appended at the end of the document. From Table 2, it can be seen a reasonable goodness of fit index (GofF) reached for almost all refinements, indicating an acceptable structure simulation of experimental data. An exemption is Z4 refinement, that presented high residuals possibly due to the low intensities of diffracting peaks, and as a result, the high noise coming from the amorphous substrate. Lattice parameters, $a(3.250 \pm 0.003)$ and $c(5.207 \pm 0.005)$ and $c / a$ ratio $(1.602 \pm 0.003)$ obtained by refinement show typical values of wurtzite type structure of $\mathrm{ZnO}$.

Four models $\vec{P}_{\mathrm{hkl}}$ of PO were assumed for each sample giving a total of 56 cases; in all the cases, the residuals $R_{p}$ and $R_{\mathrm{wp}}$ of the vectors were very low and did not exceed the 0.7 of standard deviation. For this reason, the selection of the $\mathrm{PO}$ vector was based on the higher percentage of volume oriented in each sample and not on the less residuals $R_{p}$ and $R_{\mathrm{wp}}$. The total results of 56 refinements were not shown in Table 2; only were presented these results that belong to the selected PO models. In all cases, the $\vec{P}_{101}$ model normal to (101) plane was selected. The volume of oriented crystals (see Table 2) associated to these models vary from 4.7 to $18 \%$ with a mean volume of $11.3 \%$, indicating that this CBD synthesis results in low-aligned materials (low texture) unlike previously reported works $[23,24,50]$. According to MarchDollase function, the values of $G_{1}$ parameter indicate shape diffracting domains: platelet or needle-like. In all cases, the refined parameter $G_{1}$ of (101) plane was $<1$, then plateletlike habits resulted.

Figure 9 shows (101) planes, and it compares shapes of habits in low-index planes. If the area of the section increased, the shape of the habits approaches to platelettype. The (101) plane habit can be seen as an array of distorted hexagonal platelet. When $\vec{P}_{101}, \vec{P}_{110}$, and $\vec{P}_{110}$. PO models were chosen, the platelet habits result $\left(G_{1}<1\right)$. On the contrary, the (002) plane has the smaller sectional area in a nanorod; when $\vec{P}_{002}$ model was selected (results not included), $G_{1}$ became slightly $>1$ (in all cases), which means that needle-like habits were obtained.

The (101) model of PO is discussed here. In Figure 10 is sketched a cross-sectional cut of hexagonal inclined $\mathrm{ZnO}$ rod and the diffraction conditions in both BB and GIXRD configuration. During the scanning in GIXRD experiment, the detector finds a reinforced scattering of X-rays at $\left(2 \theta_{\text {Bragg }}-\omega\right)$ position with a dispersion vector normal to diffracting planes (not to the surface) named $\vec{Q}_{A S}$. In contrary to $\mathrm{BB}$ geometry, the planes parallel to the surface will not diffract in GIXRD, unless $\theta_{\text {Bragg }}=\omega$. Only one angle of rod inclination, $(\gamma)$, satisfies $\vec{Q}_{\text {AS }}$ condition for any diffracted intensity $(i)$, and this inclination can be expressed as

$$
\gamma_{i}=\theta-\frac{\left(2 \theta_{\mathrm{Bragg}, i}-\omega\right)}{2},
$$

where $\theta$ is the angle between (hkl) plane and the axial [001] vector; $\omega$ is the incidence angle, and $2 \theta_{\text {Bragg, }}$ is the Bragg angle for the intensity $i$. Some values of $\mathrm{ZnO}$ nanorod's inclinations, $\gamma$, calculated using (8) are presented in Table 3. The calculated angle in (101) corresponds to the inclination of oriented $\mathrm{ZnO}$ population in Bragg condition (quantified in fraction-oriented volume), and it is consistent with SEM images. 


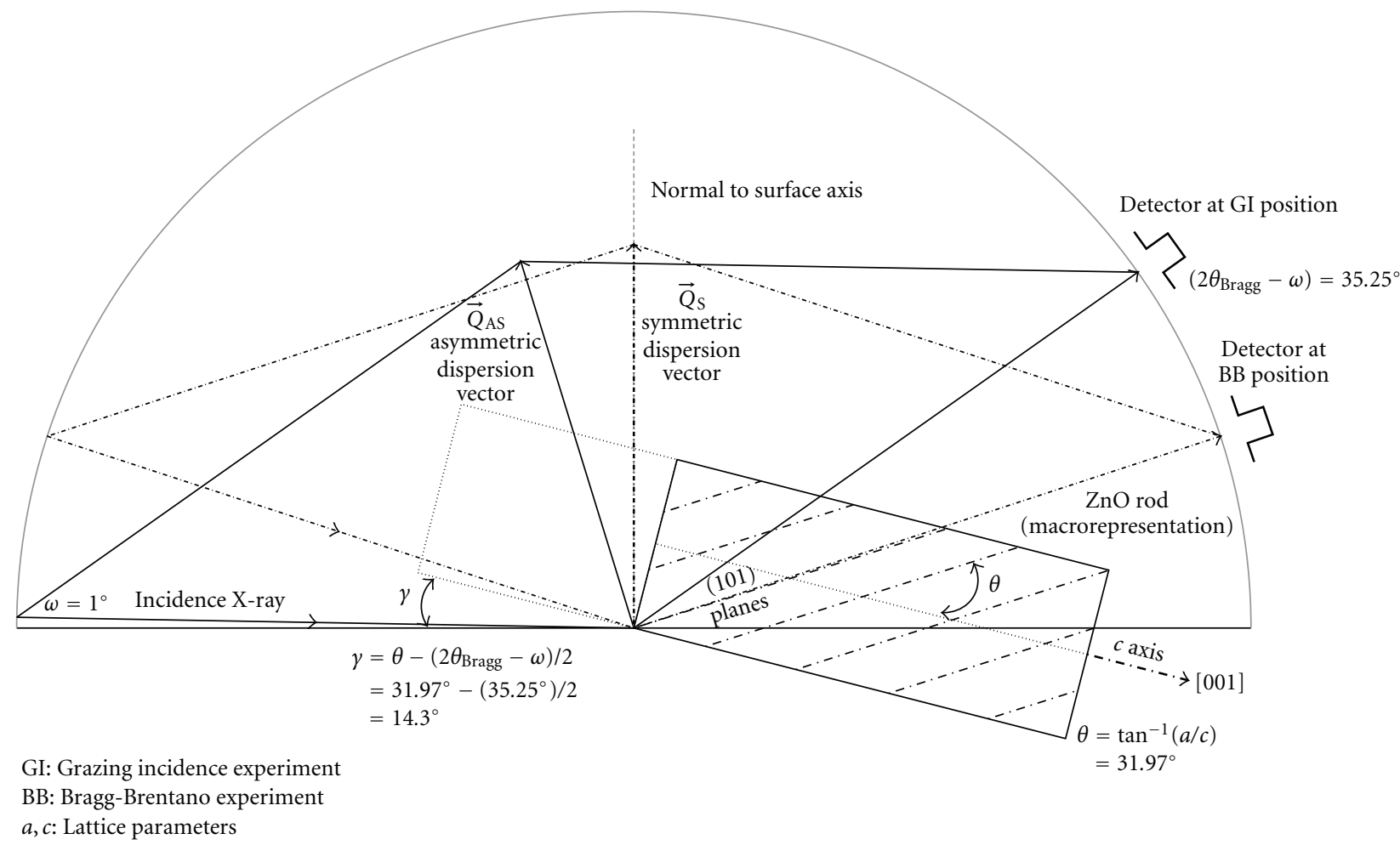

FIGURE 10: Bragg condition of (101) planes in GIXRD and BB geometry.

TABLe 4: Crystallite domains and dimension ratio obtained by GIXRD and SEM (units in nanometers). * Poor quality in diffraction data.

\begin{tabular}{|c|c|c|c|c|c|c|}
\hline \multirow{3}{*}{ Sample } & \multirow{2}{*}{\multicolumn{3}{|c|}{$\begin{array}{c}\text { GIXRD } \\
\text { Crystallite domains, } L_{\mathrm{hkl}}\end{array}$}} & \multicolumn{3}{|c|}{ SEM } \\
\hline & & & & \multirow{2}{*}{$L$} & \multirow{2}{*}{$D$} & \multirow{2}{*}{$L / D$} \\
\hline & Normal to (002) planes & Normal to (100) planes & $L_{002} / L_{100}$ & & & \\
\hline $\mathrm{Z} 1$ & 228 & 112 & 2.0 & $1341 \pm 343$ & $467 \pm 109$ & 2.9 \\
\hline $\mathrm{Z} 2$ & 264 & 119 & 2.2 & $1706 \pm 317$ & $422 \pm 170$ & 4.0 \\
\hline $\mathrm{Z3}$ & 205 & 86 & 2.4 & $2221 \pm 533$ & $443 \pm 123$ & 5.0 \\
\hline $\mathrm{Z}^{*}$ & $16 *$ & $73^{*}$ & $0.2^{*}$ & $1934 \pm 375$ & $369 \pm 97$ & 5.2 \\
\hline $\mathrm{Z} 5$ & 151 & 125 & 1.2 & $1283 \pm 225$ & $221 \pm 58$ & 5.8 \\
\hline Z6 & 136 & 118 & 1.2 & $1278 \pm 233$ & $238 \pm 48$ & 5.4 \\
\hline $\mathrm{Z7}$ & 184 & 105 & 1.7 & $821 \pm 175$ & $115 \pm 30$ & 7.1 \\
\hline Z8 & 222 & 97 & 2.3 & $1280 \pm 270$ & $173 \pm 45$ & 7.4 \\
\hline Z9 & 140 & 92 & 1.5 & $1889 \pm 329$ & $444 \pm 102$ & 4.3 \\
\hline $\mathrm{Z} 10$ & 148 & 112 & 1.3 & $2109 \pm 484$ & $498 \pm 73$ & 4.2 \\
\hline Z11 & 154 & 126 & 1.2 & $1669 \pm 377$ & $599 \pm 189$ & 2.8 \\
\hline $\mathrm{Z} 12$ & 242 & 98 & 2.5 & $1762 \pm 445$ & $470 \pm 126$ & 3.7 \\
\hline Z13 & 295 & 91 & 3.2 & $1425 \pm 420$ & $331 \pm 149$ & 4.3 \\
\hline Z14 & 270 & 111 & 2.4 & $1803 \pm 771$ & $437 \pm 182$ & 4.1 \\
\hline
\end{tabular}

Size values related to length ( $L_{002}$ or $L$ ), diameter $\left(L_{100}\right.$ or $D$ ), and $L / D$ ratio obtained by Rietveld refinement, and also from SEM images, are presented in Table 4.

The nature of evident differences of length and diameter in the techniques is related to the size of the coherent domains rather than the grain size obtained by scanning microscopy [51]. However, two aspects of the $L / D$ ratio will be briefly treated next. First, some information can give the shape of diffracting domains. Low values of $L / D$ ratios obtained by GIXRD regarding which SEM values could be indicative of anisotropy in diffracting domains, is not as high as in nanorods. Ratios of 1.2 to 3 suggest semielliptical domains, and they agree with platelet-typecalculated habits. And second is the nature of GIXRD 
technique. A low resolution with a strong peak broadening in GIXRD compared to parafocusing geometry could indicate that the values obtained are in the resolution limit to this optical arrangement. In spite of that, the second experiment (Z9-Z14) ratio tendency is the same as the obtained by SEM.

Overall isotropic temperature factor $B$ and $z$ position of oxygen atom were also refined. These parameters are intensity dependent unlike these related to peak broadening (e.g., size effects) or peak position (e.g., lattice parameters). The GIXRD experimental data has been corrected as described before divided by a factor near to 2 in all the scanning range. Although the intensity has been divided, the average $B$ of 1.74 $\pm 0.6 \AA^{2}$ and $z$ values lie in range.

\section{Conclusions}

The growth of $\mathrm{ZnO}$ nanorods was realized by CBD seedassisted synthesis. The concentrations of both ZN and HMT reactants influenced directly on the diameter of nanorod; this was determined by the availability of zinc source for the growing of nanorods over constant nucleation centers and the concentration of precipitant agent. However, hollowedtype structures were formed when $\mathrm{OH}^{-}$excess by HMT hydrolysis was present.

Rietveld analysis of GIXRD-corrected data has been performed. Correction of asymmetrical to symmetrical diffraction condition is a formalism that lets us combine the use of refinement software FullProf with a surfacesensitive X-ray characterization technique. The information obtained by refinement from reflection position and peak shape did not change with correction as intensity-dependant parameters $\left(B_{\mathrm{ov}}, z\right)$ did. Results show typical $c / a$ values of 1.602 , a unique PO vector (101) to define the main volumeoriented rod population, and finally crystallite size that suggests elliptical diffracting domains.

\section{Acknowledgments}

The authors appreciate the technical assistance from Enrique Torres, Carlos Ornelas, Silvia Miranda, and Miriam Moreno (CIMAV, Chihuahua).

\section{References}

[1] Z. Gao, Y. Gu, and Y. Zhang, "First-principles studies on the structural transition of $\mathrm{ZnO}$ nanowires at high pressure," Journal of Nanomaterials, vol. 2010, Article ID 462032, 5 pages, 2010.

[2] D. P. Singh, "Synthesis and growth of $\mathrm{ZnO}$ nanowires," Science of Advanced Materials, vol. 2, no. 3, pp. 245-272, 2010.

[3] S. K. Mohanta, D. C. Kim, B. H. Kong, H. K. Cho, W. Liu, and S. Tripathy, "Optical properties of $\mathrm{ZnO}$ nanorods and hybrid structures grown on p-type GaN/sapphire and siliconon-insulator substrates," Science of Advanced Materials, vol. 2, no. 1, pp. 64-68, 2010.

[4] L. Irimpan, V. P. N. Nampoori, and P. Radhakrishnan, "Optical limiting in $\mathrm{ZnO}$ nanocomposites," Science of Advanced Materials, vol. 2, no. 4, pp. 578-582, 2010.
[5] X. Wang, J. Song, J. Liu, and Z. L. Wang, "Direct-current nanogenerator driven by ultrasonic waves," Science, vol. 316, no. 5821, pp. 102-105, 2007.

[6] Y. Xi, J. Song, S. Xu et al., "Growth of $\mathrm{ZnO}$ nanotube arrays and nanotube based piezoelectric nanogenerators," Journal of Materials Chemistry, vol. 19, no. 48, pp. 9260-9264, 2009.

[7] Z. L. Wang and J. Song, "Piezoelectric nanogenerators based on zinc oxide nanowire arrays," Science, vol. 312, no. 5771, pp. 243-246, 2006.

[8] A. B. Djurišić, A. M. C. Ng, and X. Y. Chen, "ZnO nanostructures for optoelectronics: material properties and device applications," Progress in Quantum Electronics, vol. 34, no. 4, pp. 191-259, 2010.

[9] F. Tuomisto, "Vacancy profiles and clustering in light-ionimplanted GaN and ZnO," Applied Surface Science, vol. 255, no. 1 , pp. 54-57, 2008.

[10] U. Pal, J. G. Serrano, P. Santiago, G. Xiong, K. B. Ucer, and R. T. Williams, "Synthesis and optical properties of $\mathrm{ZnO}$ nanostructures with different morphologies," Optical Materials, vol. 29, no. 1, pp. 65-69, 2006.

[11] J. H. Yu and G. M. Choi, "Selective $\mathrm{CO}$ gas detection of $\mathrm{CuO}-$ and $\mathrm{ZnO}$-doped $\mathrm{SnO}_{2}$ gas sensor," Sensors and Actuators B, vol. 75, no. 1-2, pp. 56-61, 2000.

[12] A. Z. Sadek, W. Wlodarski, Y. X. Li et al., "A ZnO nanorod based layered $\mathrm{ZnO} / 64^{\circ} \mathrm{YX} \mathrm{LiNbO}_{3} \mathrm{SAW}$ hydrogen gas sensor," Thin Solid Films, vol. 515, no. 24, pp. 8705-8708, 2007.

[13] J. Xu, Y. Zhang, Y. Chen, Q. Xiang, Q. Pan, and L. Shi, "Uniform $\mathrm{ZnO}$ nanorods can be used to improve the response of $\mathrm{ZnO}$ gas sensor," Materials Science and Engineering B, vol. 150, no. 1, pp. 55-60, 2008.

[14] H. Zhang, N. Du, B. Chen, D. Li, and D. Yang, "Carbon nanotube- $\mathrm{ZnO}$ nanosphere heterostructures: low-temperature chemical reaction synthesis, photoluminescence, and their application for room temperature $\mathrm{NH}_{3}$ gas sensor," Science of Advanced Materials, vol. 1, pp. 13-17, 2009.

[15] X. Xu, X. Fang, H. Zeng, T. Zhai, Y. Bando, and D. Golberg, "One-dimensional nanostructures in porous anodic alumina membranes," Science of Advanced Materials, vol. 2, no. 3, pp. 273-294, 2010.

[16] H. Zeng, J. Cui, B. Cao, U. Gibson, Y. Bando, and D. Golberg, "Electrochemical deposition of $\mathrm{ZnO}$ nanowire arrays: organization, doping, and properties," Science of Advanced Materials, vol. 2, no. 3, pp. 336-358, 2010.

[17] G. Shen and D. Chen, "1-D hetero-nanostructures: from growth to devices," Science of Advanced Materials, vol. 1, pp. 213-226, 2009.

[18] S. Xu, Y. Qin, C. Xu, Y. Wei, R. Yang, and Z. L. Wang, "Selfpowered nanowire devices," Nature Nanotechnology, vol. 5, no. 5, pp. 366-373, 2010.

[19] Z. L. Wang, " $\mathrm{ZnO}$ nanowire and nanobelt platform for nanotechnology," Materials Science and Engineering R, vol. 64, no. 3-4, pp. 33-71, 2009.

[20] R. A. Rosenberg, M. Abu Haija, K. Vijayalakshmi, J. Zhou, $\mathrm{S}$. $\mathrm{Xu}$, and $\mathrm{Z}$. L. Wang, "Depth resolved luminescence from oriented ZnO nanowires," Applied Physics Letters, vol. 95, no. 24, Article ID 243101, 2009.

[21] M. Lucas, Z. L. Wang, and E. Riedo, "Growth direction and morphology of $\mathrm{ZnO}$ nanobelts revealed by combining in situ atomic force microscopy and polarized Raman spectroscopy," Physical Review B, vol. 81, no. 4, Article ID 045415, 2010.

[22] M. Lucas, Z. L. Wang, and E. Riedo, "Combined polarized Raman and atomic force microscopy: in situ study of point defects and mechanical properties in individual $\mathrm{ZnO}$ 
nanobelts," Applied Physics Letters, vol. 95, no. 5, Article ID 051904, 2009.

[23] S. Xu, Y. Wei, M. Kirkham et al., "Patterned growth of vertically aligned $\mathrm{ZnO}$ nanowire arrays on inorganic substrates at low temperature without catalyst," Journal of the American Chemical Society, vol. 130, no. 45, pp. 14958-14959, 2008.

[24] S. Xu, C. Lao, B. Weintraub, and Z. L. Wang, "Densitycontrolled growth of aligned $\mathrm{ZnO}$ nanowire arrays by seedles chemical approach on smooth surfaces," Journal of Materials Research, vol. 23, no. 8, pp. 2072-2077, 2008.

[25] Y. Gan, F. Gu, D. Han, Z. Wang, and G. Guo, "Biomimetic synthesis of zinc oxide 3D architectures with gelatin as matrix," Journal of Nanomaterials, vol. 2010, Article ID 289173, 2010.

[26] L. Schmidt-Mende and J. L. MacManus-Driscoll, "ZnO nanostructures, defects, and devices," Materials Today, vol. 10, no. 5, pp. 40-48, 2007.

[27] J. Ye and L. Qi, "Solution-phase synthesis of one-dimensional semiconductor nanostructures," Journal of Materials Science and Technology, vol. 24, no. 4, pp. 529-540, 2008.

[28] B. Tang, H. Deng, Z. W. Shui, and Q. Zhang, "Synthesis and optical properties of vertically aligned $\mathrm{ZnO}$ nanorods," Journal of Nanoscience and Nanotechnology, vol. 10, no. 3, pp. 1842$1845,2010$.

[29] L. Vayssieres, "On the design of advanced metal oxide nanomaterials," International Journal of Nanotechnology, vol. 1, no. 1-2, pp. 1-41, 2004.

[30] P. Hari, M. Baumer, W. D. Tennyson, and L. A. Bumm, “ZnO nanorod growth by chemical bath method," Journal of NonCrystalline Solids, vol. 354, no. 19-25, pp. 2843-2848, 2008.

[31] R. Ding, J. Liu, J. Jiang et al., "A general solution synthesis route to $\mathrm{ZnO}$-based nanorod arrays on ceramic/silicon/quartz glass/metal substrates," Science of Advanced Materials, vol. 2, no. 3, pp. 396-401, 2010.

[32] D. Vernardou, G. Kenanakis, S. Couris, E. Koudoumas, E. Kymakis, and N. Katsarakis, "pH effect on the morphology of $\mathrm{ZnO}$ nanostructures grown with aqueous chemical growth," Thin Solid Films, vol. 515, no. 24, pp. 8764-8767, 2007.

[33] K. Govender, D. S. Boyle, P. B. Kenway, and P. O'Brien, "Understanding the factors that govern the deposition and morphology of thin films of $\mathrm{ZnO}$ from aqueous solution?" Journal of Materials Chemistry, vol. 14, no. 16, pp. 2575-2591, 2004.

[34] X. M. Liu and Y. C. Zhou, "Seed-mediated synthesis of uniform $\mathrm{ZnO}$ nanorods in the presence of polyethylene glycol," Journal of Crystal Growth, vol. 270, no. 3-4, pp. 527$534,2004$.

[35] J. Rodríguez-Carvajal, "Recent advances in magnetic structure determination by neutron powder diffraction," Physica B, vol. 192, no. 1-2, pp. 55-69, 1993.

[36] T. Roisnel and J. Rodriguez-Carvajal, "A Windows tool for powder diffraction patterns analysis," in Proceedings of the 7th European Powder Diffraction Conference, Materials Science Forum (EPDIC'00), 2000

[37] H. Toraya and T. Okuda, "Crystal structure analysis of polycrystalline $\mathrm{Bi}_{3} \mathrm{Fe}_{5} \mathrm{O}_{12}$ thin film by using asymmetric and symmetric diffraction techniques," Journal of Physics and Chemistry of Solids, vol. 56, no. 10, pp. 1317-1322, 1995.

[38] R. W. James, in The Crystalline State, The Optical Principle of the Diffraction of X-Rays. Vol. II, Chap. VIII, pp. 413-438, G. Bell and Sons, London, UK, 1962.

[39] N. A. Raftery, L. K. Bekessy, and J. Bowpitt, "Analysis of low mass absorption materials using glancing incidence X-ray diffraction," in Advances in X-ray Analysis, JCPDSInternational Centre for Diffraction Data, 2006.
[40] M. Miki-Yoshida, F. Paraguay-Delgado, W. Estrada-López, and E. Andrade, "Structure and morphology of high quality indium-doped $\mathrm{ZnO}$ films obtained by spray pyrolysis," Thin Solid Films, vol. 376, no. 1-2, pp. 99-109, 2000.

[41] Y. I. Kim and K. H. Kim, "Application of pole figures to Rietveld Refinement," Journal of Materials Science Letters, vol. 19, no. 14, pp. 1251-1252, 2000.

[42] M. Wei, D. Zhi, and D. G. Brandon, "Microstructure and texture evolution in gel-cast $\alpha$-alumina/alumina platelet ceramic composites," Scripta Materialia, vol. 53, no. 12, pp. 1327-1332, 2005.

[43] A. A. Ramadan, A. A. Abd El-Mongy, A. M. El-Shabiny et al., "Addressing difficulties in using XRD intensity for structural study of thin films," Crystal Research and Technology, vol. 44, no. 1, pp. 111-116, 2009.

[44] L. Vayssieres, "An aqueous solution approach to advanced metal oxide arrays on substrates," Applied Physics A, vol. 89, no. 1, pp. 1-8, 2007.

[45] Z. Chen and L. Gao, "A facile route to $\mathrm{ZnO}$ nanorod arrays using wet chemical method," Journal of Crystal Growth, vol. 293, no. 2, pp. 522-527, 2006.

[46] X. Liu, Z. Jin, S. Bu, J. Zhao, and Z. Liu, "Growth of ZnO films with controlled morphology by aqueous solution method," Journal of the American Ceramic Society, vol. 89, no. 4, pp. 1226-1231, 2006.

[47] S. C. Liou, C. S. Hsiao, and S. Y. Chen, "Growth behavior and microstructure evolution of $\mathrm{ZnO}$ nanorods grown on $\mathrm{Si}$ in aqueous solution," Journal of Crystal Growth, vol. 274, no. 3-4, pp. 438-446, 2005.

[48] J. I. Kroschwitz, Ed., Kirk-Othmer Encyclopedia of Chemical Technology, Vol. 25, 4th edition, 1998.

[49] R. D. Tarey, R. S. Rastogi, and K. L. Chopra, "Characterization of thin films by glancing incidence X-Ray diffraction," The Rigaku Journal, vol. 4, no. 1, pp. 11-15, 1987.

[50] W. Mai, P. Gao, C. Lao et al., "Vertically aligned $\mathrm{ZnO}$ nanowire arrays on GaN and SiC substrates," Chemical Physics Letters, vol. 460, no. 1-3, pp. 253-256, 2008.

[51] J. I. Langford, "Crystallite size from diffraction data," in Newsletter of Commission on Powder Diffraction, pp. 11-14, International Union of Crystallography, 2000. 

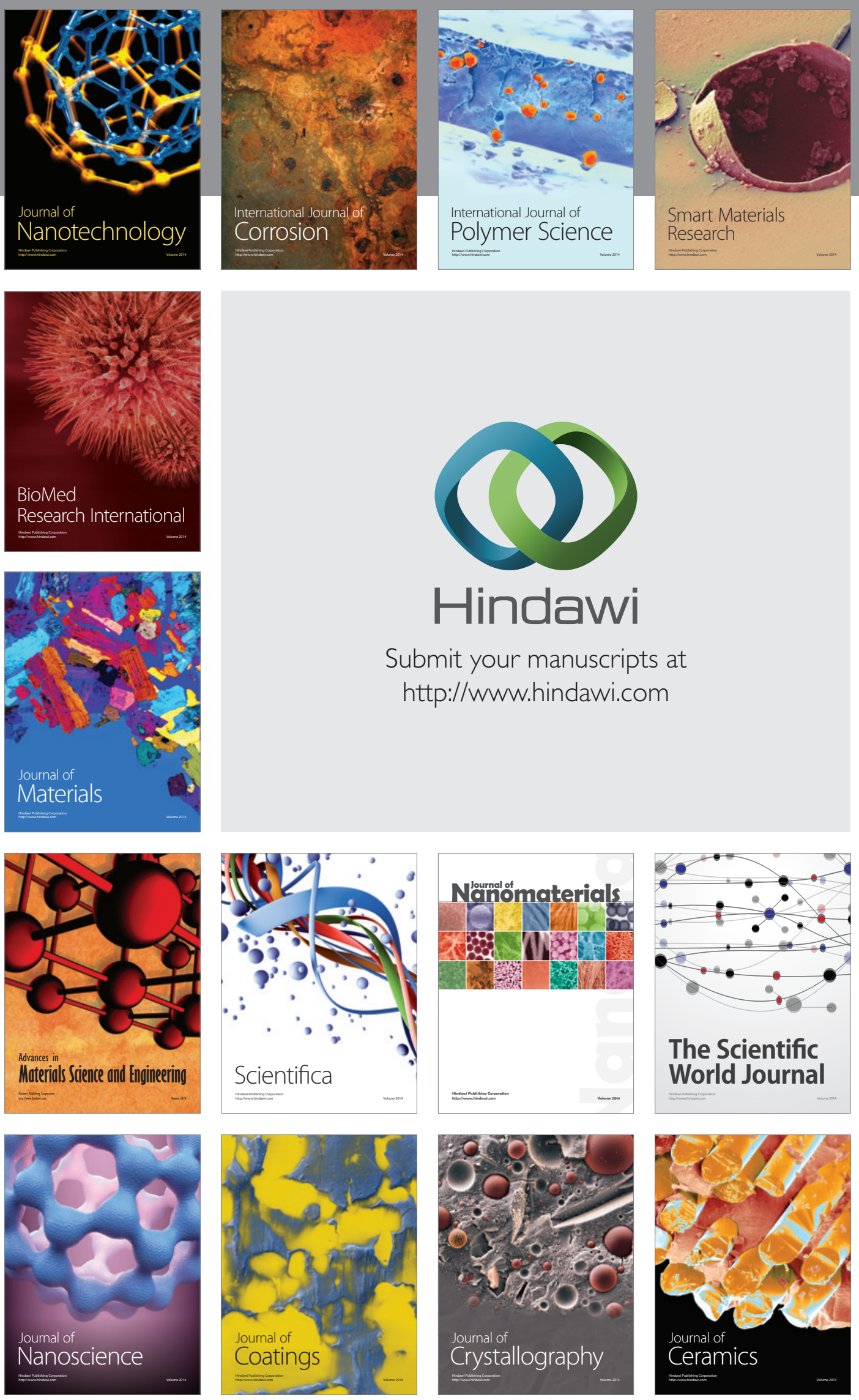

The Scientific World Journal

Submit your manuscripts at

http://www.hindawi.com

\section{World Journal}

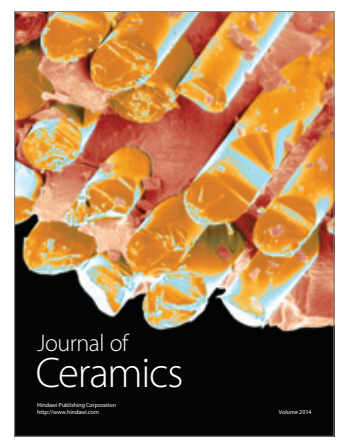

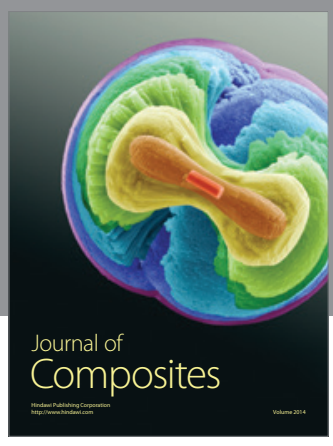
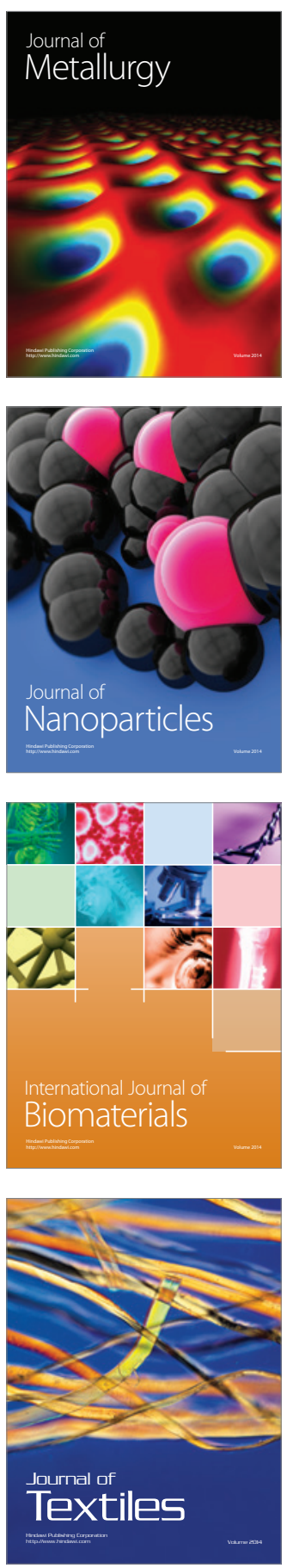